\title{
Jump Diffusion Modeling of Stock Prices on Ghana Stock Exchange
}

\author{
Osei Antwi ${ }^{*}$, Kyere Bright ${ }^{2}$, Kwasi Awuah Wereko³ \\ ${ }^{1}$ Mathematics \& Statistics Department, Accra Technical University, Accra, Ghana \\ ${ }^{2}$ Accountancy Department, Accra Technical University, Accra, Ghana \\ ${ }^{3}$ Business School, Ghana Institute of Public Administration (GIMPA), Accra, Ghana \\ Email: *oseiantwi@yahoo.co.uk
}

How to cite this paper: Antwi, O., Bright, K. and Wereko, K.A. (2020) Jump Diffusion Modeling of Stock Prices on Ghana Stock Exchange. Journal of Applied Mathematics and Physics, 8, 1736-1754. https://doi.org/10.4236/jamp.2020.89131

Received: July 20, 2019

Accepted: September 4, 2020

Published: September 7, 2020

Copyright $\odot 2020$ by author(s) and Scientific Research Publishing Inc. This work is licensed under the Creative Commons Attribution International License (CC BY 4.0).

http://creativecommons.org/licenses/by/4.0/ (c) (i) Open Access

\begin{abstract}
The behaviour of stocks on the Ghana stock exchange is examined to show that stock prices on the exchange are subject to sudden price changes. It is shown that such unexpected events and uncertainties affecting trading on the exchange cannot be modeled solely by the conventional geometric Brownian motion outlined in the Black-Scholes model. A new concise and simpler approach is developed to derive the Jump diffusion model and consequently, its suitability to model stocks on the exchange is emphasized and given rigorous treatment. The model is subsequently used to predict the behaviour of stocks using historical stock prices as input parameters. The simulated stock returns are compared to actual returns to determine the model's suitability to predict the market. The results show that the jump diffusion model is appropriate in predicting the behaviour of approximately $25 \%$ percent of stocks listed on the exchange.
\end{abstract}

\section{Keywords}

Diffusion, Jump Diffusion, Skewness, Kurtosis, Jump Sizes

\section{Introduction}

The modeling of stock price behaviour has generally been realized through the use of diffusion processes. The fundamental model for a stock following a diffusion process consists of a deterministic drift and stochastic parts and it's known generally as Geometric Brownian Motion (GBM). Under GBM the stock returns are lognormally distributed largely ensuring non-negative prices. Although GBM has been successful in modelling stock price processes, it is unable to account for the presence of sudden or occasional jumps, which has been observed 
in many stock markets. Recent empirical evidence from the Ghana Stock Exchange (GSE) suggests that some stocks are characterized by sudden price fluctuations. These observations have motivated the need to critically examine models used to price the behaviour of stocks on the Exchange. Empirical data from December 2016 to December 2017 show that the Ghana Stock Exchange Composite Index recorded a return of 52.73\%. Notably, some stocks posted unusually high returns-Benso Oil Palm Plantation Limited (194.23\%), Ghana Oil Company Limited (144.55\%), Standard Chartered Bank Limited (106.8\%), HFC Bank Limited (85.33\%) and Total Petroleum Ghana Limited (76.5\%). Such return behaviour implicitly suggests the presence of sudden price changes giving rise to high skewness and kurtosis in the return distribution of the stock. Figures 1-3 show the 5-year return distribution of some stocks listed on GSE. The sudden peaks represent jumps in the stock prices distribution.

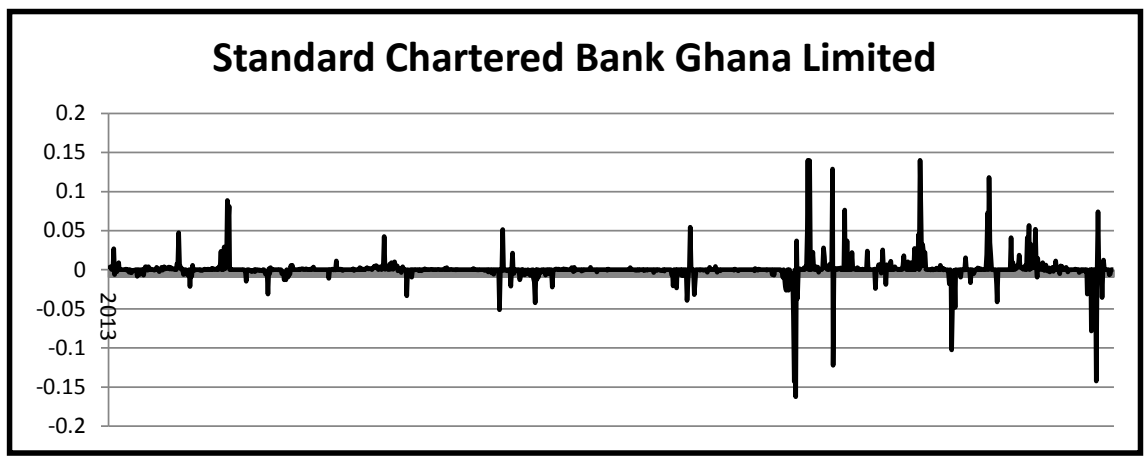

Figure 1. Logarithmic returns of Standard Chartered Bank Ghana stocks 2013-2018.

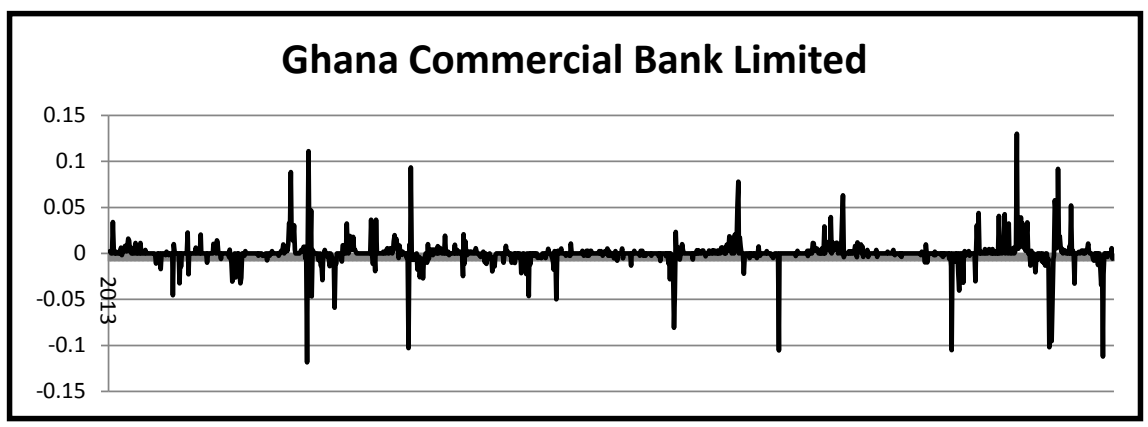

Figure 2. Logarithmic returns of Ghana Commercial Bank stocks 2013-2018.



Figure 3. Logarithmic returns of Ecobank Ghana stocks 2013-2018. 


\section{Empirical Evidence}

Figures 1-3 show the log-return graphs of three stocks listed on GSE; Standard Chartered Bank Ghana, Ghana Commercial Bank and Ecobank Ghana respectively, from January 2013 to December 2018. The log-return graphs show increasing activity in the stock market leading to observed higher number of jumps from 2016 to 2018. A typical example is the stock of Standard Chartered Bank in which there were no jumps from 2013 to middle of 2016. However, from December 2016 to June 2018, there were at least nine jumps. Similar jump patterns are observed in Ecobank stock price as shown in Figure 2. For this stock there was only one jump from 2013 to the end of 2016, but 2017 experienced several jumps. Theoretically, jumps occur as a result of the release of new information especially when it is firm specific leading to a sudden spike in the price distribution. Such spontaneous increase in price causes discontinuities in the stock's price path, given rise to leptokurtic features in the return distribution. Under such conditions the empirical log returns of the prices are no longer normally distributed but characterized by fat tails and excess kurtosis. For this reason, knowledge of skewness and kurtosis of the log return distributions provide insights into the jump behavior of a stock. The estimates of skewness and kurtosis are obtained using Equation (1) and Equation (2) respectively.

$$
\begin{aligned}
& \text { Skewness } S=\frac{1}{(n-1) \sigma^{3}} \sum_{i=1}^{n}\left(X_{i}-\bar{X}\right)^{3} \\
& \text { kurtosis } K=\frac{1}{(n-1) \sigma^{4}} \sum_{i=1}^{n}\left(X_{i}-\bar{X}\right)^{4}
\end{aligned}
$$

where $\sigma$ is the standard deviation of a stock's return.

For the standard normal density, $S=0$ and $K=3$ in Equations (1) and (2) respectively. If $S$ and $K$ are different from 0 and 3 then the distribution will be called leptokurtic and will have higher peaks and heavier (fat) tails than those of the normal distribution. For stocks listed on Ghana stock exchange in 2017, the skewness and kurtosis as well as the means and volatilities are given in Table 1.

The results in Table 1 show that several stocks exhibited skewness and kurtosis far in excess of 0 and 3 respectively. This confirms the presence of jumps in some stock price returns and as such there is the need to critically review approaches of stock modeling in regards to the exchange. One problem for investors on Ghana stock exchange is the absence of models to predict stock behaviour. Even in cases where models exist closed form expressions for the stock density are generally are not available. Antwi (2017) [1] used GBM to model stock behaviour on the exchange but in the light of current evidence it is essential to consider the use of other models for some stocks. Thus, the aim of this paper is to examine the use of Jump Diffusion Model (JDM) to predict stock price behaviour on the exchange. The use of JDM will ensure that the jump behaviour exhibited by some stocks can be incorporated into stock price modeling on the exchange. 
Table 1. Skewness and Kurtosis of log returns of stocks listed on GSE for 2017.

\begin{tabular}{|c|c|c|c|c|c|c|c|c|c|c|}
\hline Stock & $\begin{array}{c}\text { African } \\
\text { Champion }\end{array}$ & Anglo Gold & Aluworks & Ayrton Drug & Benso & Cal Bank & Clydestone & Camelot & $\begin{array}{c}\text { Cocoa } \\
\text { Processing }\end{array}$ & \\
\hline Skewness & 1.561 & 0.000 & 0.953 & -0.257 & -1.895 & -1.004 & 0.796 & 0.678 & -0.658 & \\
\hline Kurtosis & 3.226 & 0.000 & -0.193 & -1.156 & -0.581 & 21.159 & -1.369 & -1.271 & -1.571 & \\
\hline Mean & 0.00 & 0.00 & 0.0005428 & -0.0007411 & 0.004387 & 0.001428 & 0.00 & -0.00035 & $4.51 \mathrm{E}-19$ & \\
\hline Volatility & 0.00 & 0.00 & 0.0168687 & 0.0116244 & 0.018568 & 0.031976 & 0.00 & 0.005548 & 0.072554 & \\
\hline Stock & $\begin{array}{c}\text { Ecobank } \\
\text { Ghana }\end{array}$ & $\begin{array}{c}\text { Enterprise } \\
\text { Group }\end{array}$ & $\begin{array}{c}\text { Ecobank } \\
\text { Transnational }\end{array}$ & Fan Milk & $G C B$ & Guinness & $G O I L$ & $\begin{array}{l}\text { Golden } \\
\text { Star }\end{array}$ & Golden Web & \\
\hline Skewness & 1.496 & 1.348 & 0.092 & -0.696 & -0.688 & -3.775 & -0.120 & 0.310 & -0.128 & \\
\hline Kurtosis & 0.692 & -1.110 & 5.159 & 0.646 & -1.244 & 6.718 & -0.583 & -1.574 & -1.584 & \\
\hline Mean & 0.00063555 & 0.00176 & 0.0019106 & 0.0018604 & 0.001376 & 0.000952 & 0.003635 & -0.00011 & 0.00 & \\
\hline Volatility & 0.01326269 & 0.018091 & 0.0341023 & 0.0119202 & 0.011604 & 0.010731 & 0.011702 & 0.001723 & 0.00 & \\
\hline Stock & $H F C$ & $\begin{array}{l}\text { Mechanical } \\
\text { Lloyd }\end{array}$ & $\begin{array}{c}\text { Pioneer } \\
\text { Kitchenware }\end{array}$ & $\begin{array}{l}\text { Produce } \\
\text { Buying }\end{array}$ & $\begin{array}{c}\text { PZ } \\
\text { Cussons }\end{array}$ & $\begin{array}{l}\text { Standard } \\
\text { Chartered }\end{array}$ & $S I C$ & $\begin{array}{l}\text { Starwin } \\
\text { Products }\end{array}$ & $S G-S S B$ & \\
\hline Skewness & -1.139 & -0.465 & -0.174 & -0.183 & -0.001 & 0.270 & -0.157 & -0.175 & -0.664 & \\
\hline Kurtosis & -1.021 & 26.342 & -1.974 & -0.527 & -0.022 & -0.026 & 12.595 & -1.302 & 0.092 & \\
\hline Mean & 0.00250807 & -0.00372 & 0.00 & $-2.031 \mathrm{E}-18$ & -0.00039 & 0.002954 & -0.00074 & $2.71 \mathrm{E}-18$ & 0.001137 & \\
\hline Volatility & 0.02179135 & 0.020868 & 0.00 & 0.04573 & 0.006077 & 0.021696 & 0.037589 & 0.084415 & 0.010978 & \\
\hline Stock & Sam Woode & Trust Bank & TOTAL & $\begin{array}{l}\text { Transaction } \\
\text { Solutions }\end{array}$ & Tullow Oil & Unilever & UT Bank & $\begin{array}{l}\text { Mega } \\
\text { African }\end{array}$ & $A D B$ & $\begin{array}{c}\text { Access } \\
\text { Bank }\end{array}$ \\
\hline Skewness & -1.547 & -0.911 & 5.022 & 2.691 & -7.792 & 0.477 & -0.554 & -0.292 & 0.174 & -0.333 \\
\hline Kurtosis & 1.425 & -1.703 & 24.354 & 5.252 & -1.451 & -1.579 & -1.368 & -1.244 & -1.776 & -0.872 \\
\hline Mean & 0.00090709 & 0.001208 & 0.0023096 & 0.00 & -0.00183 & 0.001672 & 0.003984 & $-1.4 \mathrm{E}-05$ & 0.001715 & $-5 \mathrm{E}-05$ \\
\hline Volatility & 0.01422711 & 0.023732 & 0.0134325 & 0.00 & 0.015226 & 0.01281 & 0.066734 & 0.00015 & 0.012896 & 0.029841 \\
\hline
\end{tabular}

The objective is to use the jump diffusion to model the dynamics of stocks behavior on the exchange. The Jump Diffusion Model is thus developed and used to simulate stock prices. The return statistics are compared with that of the market prices to determine if the model fit the market data. This paper will specifically;

- Develop the Jump Diffusion Model from first principles;

- Use Jump Diffusion Model to simulate the stock price behaviour with data from Ghana Stock Exchange;

- Identify stocks for which the Jump Diffusion Model is a suitable predictive model.

\section{Literature Review}

The literature on stock price modeling is extensive. The foundations were laid by Bachelier [2] who assumed that the stock price dynamics follows a normal distribution. Samuelson [3] modified Bachelier's model so that the stock price was log-normally distributed. The choice of a lognormal density is now standard in 
financial modeling and is known as Geometric Brownian Motion (GBM). Although GBM has been successful in modeling the continuous part (pure diffusion) of a stock price process as in Black-Scholes [4], it cannot account for discontinuities in the price trajectories which give rise to the leptokurtic features observed in the time series of empirical data.

Three approaches dominate the research to address the presence of jumps observed in empirical data: jump-diffusion, stochastic volatility and the Constant Elasticity of Variance models. Merton [5] was the first to consider the use of jump diffusion in modeling stock prices, assuming that the jumps in stocks follows a compound Poisson process allowing jump times to follow Poisson distribution and jump sizes to be normally distributed. Accordingly, several extensions and variants of jump diffusion models have been developed. Kou [6], assumed that jump sizes follow a double-exponential distribution. In Madan and Seneta [7], the distribution of the uncertainty in the stock price is Gaussian, conditional on a variance that is distributed as a gamma variate. The advantages of Madan and Seneta include the ability to track long tail distributions, continuous-time specification, finite moments, elliptical multivariate unit period distributions and being a good empirical fit. Matsuda [8], introduced an approach to jump diffusions and derived the moments, skewness and kurtosis of the model. Amin [9], developed a discrete time model which converges weakly to the diffusion component of the jump diffusion process by superimposing jumps on the existing local price changes. Multivariate jumps were superimposed on the binomial model of Cox, Ross, and Rubinstein [10] to obtain a model which converges to a limiting jump diffusion process. Cont and Tankov [11] gave a complete treatment of jump diffusion models.

In stochastic volatility models the return of the stock price follows the diffusion process but the constant volatility is replaced by a stochastic volatility. Examples include Hull and White [12], in which the instantaneous volatility is allowed to follow a stochastic process. There are several other stochastic volatility models that allow arbitrage free prices in volatile markets as in Heston [13]. Duffie, Pan and Singleton [14] examined the impact of stochastic volatility on jumps diffusion for both jump amplitude as well as jump timing in an option pricing setting. These ideas are extended in Chernov et al. [15]. Barndorff-Nielson and Shephard [16] showed that the difference between realized variance and realized bipower variation estimates the quadratic variation of the jump component when volatility is stochastic. The follow up to jump diffusion and stochastic volatility models are the Affine Stochastic-Volatility and Affine Jump-Diffusion models which combine stochastic volatility and jump-diffusions models as in Duffie [17]. The basic affine jump diffusion is a stochastic process which consists of a Geometric Brownian motion with a stochastic volatility, a compound Poisson process and an independent exponentially distributed jumps with specified mean and variance.

The Constant Elasticity of Variance (CEV) model was first proposed by Cox and Ross [18] and extended by Davydov and Linetsky [19]. CEV is a one-dimensional 
diffusion model with instantaneous volatility specified by a power function of the underlying stock price. Although introduced as an alternative to GBM the model is more related to the Bessel processes and it is analytically tractable, allowing for closed-form pricing formulas. Other models include chaos theory and fractal Brownian motions which were considered by Mandelbrot [20]. There are the Generalized hyperbolic models and log-hyperbolic model of Barndorff-Nielsen and Shephard [21], Samorodnitsky and Taqqu [22], Blattberg and Gonedes [23] which replaces the log-normal distribution assumed in GBM by some other distributions.

To implement simulation of the jump diffusion models, Glasserman [24], discussed Monte Carlo approaches of simulating the process at fixed dates and at specified jump times. Hanson [25], gives practical examples for jump-diffusions in continuous time, including jumps driven by compound Poisson process that allow randomly distributed jump-amplitudes, state-dependent jump-diffusions and multidimensional jump-diffusions. Hanson and Westman [26], compared the performance of three jump-diffusion models using normal, uniform and double-exponential jump-amplitude distributions. The parameters of all three models were fit to Standard and Poor's 500 log-return market data, given the same first moment and second central moments. Beskos and Roberts [27], introduced a simple algorithm that simulates exact sample paths of stochastic differential equations. This was extended by Casella and Roberts [28], who introduced an algorithm to simulate from a class of one-dimensional jump-diffusion processes with state-dependent intensity. Advances in simulation procedures has been carried out by Pollock, et al. [29], by introducing a framework for simulating finite dimensional representations of jump diffusion sample paths over finite intervals without discretization error.

\section{Methodology}

\subsection{Geometric Brownian Motion}

In a risky stock, the stock price $S(t)$ is assumed to follow the lognormal process and is modelled by GBM as

$$
\frac{\mathrm{d} S(t)}{S(t)}=\mu \mathrm{d} t+\sigma \mathrm{d} W(t)
$$

where $\mu$ is the expected return on the stock, $\sigma$ is the standard deviation of the return and $W(t)$ is the standard Brownian motion or Wiener process with mean 0 and standard deviation $t$.

The solution to Equation (3) is

$$
S(t)=S(0) \mathrm{e}^{\left(\mu-\frac{1}{2} \sigma^{2}\right) t+\sigma W(t)}
$$

\subsection{Developing the Jump Diffusion Model}

In modelling the dynamics of the stock price in the jump diffusion setting the trajectory of the stock consist of two components. The first component is driven 
by the normal price changes due to the effect of economic factors such as disequilibrium in supply and demand on the market. This component is expressed by a standard Brownian motion with a constant drift, a constant volatility and almost continuous paths. The second component is described by changes of the stock price influenced by new available information. This jump part of the stock process is outlined as a Poisson process and by extension a compound Poisson process.

Consider the stock price $S(t)$, understood to be right-continuous function with left limits so that $S(t-)$ represents the value of $S(t)$ just before a possible jump at $t$. We write $S(t)$ as the limit from the left, i.e.

$$
S(t-)=\lim _{S \uparrow t} S(u)
$$

Suppose that in the small-time interval $\Delta t$ the stock price jumps by $Y(t)$ so that it jumps from $S(t)$ to $Y(t) S(t)$ as shown in Figure 4.

The percentage change in the stock price is thus given by

$$
\begin{gathered}
\frac{\Delta S(t)}{S(t)}=\frac{Y(t) S(t)-S(t)}{S(t)} \\
\frac{\Delta S(t)}{S(t)}=\frac{Y(t) S(t)}{S(t)}-\frac{S(t)}{S(t)} \\
\frac{\Delta S(t)}{S(t)}=Y(t)-1
\end{gathered}
$$

In the infinitesimal limit

$$
\frac{\mathrm{d} S(t)}{S(t)}=Y(t)-1
$$

It is realized that $Y(t)$ 's are non-negative random variables modeling the distribution of the jump sizes such that they are independently identically distributed and the trajectories of jumps sizes are piecewise constant, right-continuous with left limits. Equation (6) gives the relative jump amplitude or percentage change in stock price as $(Y-1)$.

In addition to the jump sizes the inter-arrival times of the jumps needed to be modeled. The arrival times of jumps $t_{1}, t_{2}, \cdots, t_{m}$ is generated by a Poisson process $N(t)$ independent of the jump sizes $Y(t)$ with average arrival times or intensity

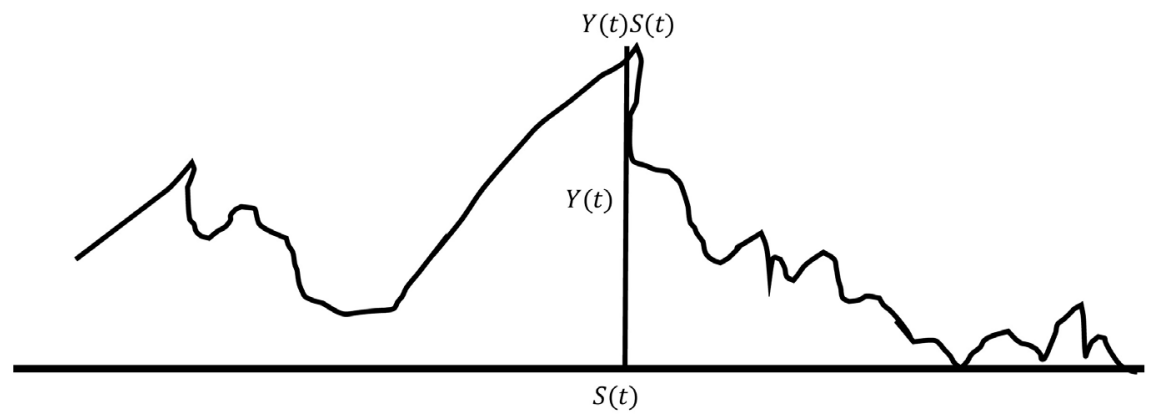

Figure 4. Evolution of a jump diffusion process. 
$\lambda$. By combining the jump times and the jump sizes the jump part of the stock price process is denoted by the compound Poisson process

$$
S(t)=\sum_{j=1}^{N(t)} Y_{i}
$$

The consequence of Equation (7) is that in a small-time interval $\mathrm{d} t$ the likelihood of the Poisson event can be described as follows:

- Probability that the stock price jumps once

$$
\begin{aligned}
& P_{r}\{\text { the stock price jumps once }\} \\
& =P_{r}\{\text { that the Poisson event } \mathrm{d} N(t) \text { occurs }\}=P_{r}\{\mathrm{~d} N(t)=1\}=\lambda \mathrm{d} t
\end{aligned}
$$

- Probability that the stock price does not jump

$$
\begin{aligned}
& P_{r}\{\text { the stock price does not jump }\} \\
& =P_{r}\{\text { the Poisson event } \mathrm{d} N(t) \text { does not occur }\}=P_{r}\{\mathrm{~d} N(t)=0\}=1-\lambda \mathrm{d} t
\end{aligned}
$$

- Probability that the stock price jumps more than once

$$
P_{r}\{\text { the stock price jumps more than once }\}=P_{r}\{\mathrm{~d} N(t) \geq 2\}=0
$$

- The random variables $Y_{i}$ defining the jump sizes are assumed to be normally distributed with mean $m$ and variance $\delta^{2}$ and has density $f$ given by

$$
f(y)=\frac{1}{\sqrt{2 \pi \delta_{i}}} \exp \left\{\frac{(y-m)^{2}}{2 \delta_{i}^{2}}\right\}
$$

- The relative jump sizes $\left(Y_{j}-1\right)$ are also lognormally distributed with expected value and variance given by

$$
\begin{aligned}
& \mathbb{E}[Y-1]=\mathrm{e}^{\mu+\frac{1}{2} \delta^{2}}-1=k \\
& \operatorname{Var}[Y]=\mathrm{e}^{2 \mu+\delta^{2}}\left(\mathrm{e}^{\delta^{2}}-1\right)
\end{aligned}
$$

- The jumps occur at times $t_{1}, t_{2}, \cdots, t_{m}$ and the intervals between jumps (the waiting times) are exponentially distributed. For $t>0, N(t)$ has the Poisson distribution with parameter $\lambda t$, that is the probability of increment of jump times is given by the Poisson distribution

$$
P_{r}[\mathrm{~d} N(t)=k]=\frac{(\lambda \mathrm{d} t)^{k} \mathrm{e}^{-\lambda \mathrm{d} t}}{k !}, k=0,1, \cdots
$$

To model the dynamics of a stock price in the jump diffusion model, it is realized that the stock price path is driven by two stochastic processes: The first is the diffusion part driven by continuous Brownian motion and modeled by lognormal geometric Brownian motion. The second is the jump part driven by Poisson jumps and modelled by the compound Poisson process derived above. Hence the equation for the stock price path is given by

$$
\mathrm{d} S(t)=\mu S(t-) \mathrm{d} t+\sigma S(t-) \mathrm{d} W(t)+S(t-) \sum_{i=1}^{N(t)} Y_{i}
$$

where $N(t)$ is a Poisson process independent of the Wiener process $W(t)$ 
with constant arrival rate $\lambda$.

$\mu$ is the constant instantaneous expected rate of return for the stock;

$\sigma$ is a constant volatility parameter of the stock.

The return distribution of the stock is given by

$$
\frac{\mathrm{d} S(t)}{S(t-)}=\mu \mathrm{d} t+\sigma \mathrm{d} W(t)+\sum_{i=1}^{N(t)} Y_{i}
$$

\subsubsection{JDM under Equivalent Martingale Measures}

In a diffusion process the market model is complete and the existence and uniqueness of an equivalent martingale measure is guaranteed. In this framework the drift is determined by the condition that discounted stock price process is a martingale. The diffusion process under the equivalent martingale measure is given by

$$
\mathrm{d} S(t)=\mu S(t) \mathrm{d} t+\sigma S(t) \mathrm{d} W(t)^{\mathbb{Q}}
$$

To ensure that $S(t)$ is a martingale the jump part of the process is compensated by $\lambda k \mathrm{~d} t$ such that the expected relative price change $\mathbb{E}\left[\frac{\mathrm{d} S}{S}\right]$ in the interval $\mathrm{d} t$ is $\mathbb{E}\left[Y_{i}-1\right]=\mathbb{E}[Y]-1=\lambda k$. The term $\lambda k$ compensates the jumps in the sense that the process $Y(t)-\lambda k t$ is a martingale. Hence, Equation (6) can be written as

$$
\begin{aligned}
& \frac{\mathrm{d} S(t)}{S(t-)}=\mu \mathrm{d} t+\sigma \mathrm{d} W(t)+\sum_{i=1}^{N(t)} Y_{i}-\lambda k \mathrm{~d} t \\
& \frac{\mathrm{d} S(t)}{S(t-)}=(\mu-\lambda k) \mathrm{d} t+\sigma \mathrm{d} W(t)+\sum_{i=1}^{N(t)} Y_{i}
\end{aligned}
$$

\section{Solution to the Jump Diffusion Model}

Suppose $S(t)$ is a stochastic process following the jump diffusion process in Equation (10) which can be rewritten as

$$
\frac{\mathrm{d} S(t)}{S(t-)}=(\mu-\lambda k) \mathrm{d} t+\sigma \mathrm{d} W(t)+h \mathrm{~d} N(t)
$$

Let $f(t)=\ln S(t)$, then in between jumps, the $\log$ expansion of the Ito process is given by

$$
\begin{aligned}
\mathrm{d} f(t, S(t))= & \left\{\frac{\partial f}{\partial t}(t, S(t))+(\mu-\lambda k) \frac{\partial f}{\partial x}(t, S(t))+\frac{1}{2} \sigma^{2} \frac{\partial^{2} f}{\partial x^{2}}(t, S(t))\right\} \mathrm{d} t \\
& +\sigma \frac{\partial f}{\partial x}(t, S(t)) \mathrm{d} W(t)
\end{aligned}
$$

At the jump time $t, N(t)$ has the jump size of $\Delta N(t)=N(t)-N(t-)=1$ and the induced jump is given by

$$
\Delta Z(t)=f(t, S(t))-f(t-, S(t-)) .
$$

The Ito expansion of JDM is now given by 


$$
\begin{gathered}
\mathrm{d} \ln S(t)=\frac{\partial \ln S(t)}{\partial t} \mathrm{~d} t+(\mu-\lambda k) \frac{\partial \ln S(t)}{\partial S(t)} \mathrm{d} t+\frac{\sigma^{2}(t) S(t)}{2} \frac{\partial^{2} \ln S(t)}{\partial S(t)^{2}} \mathrm{~d} t \\
+\sigma(t) S(t) \frac{\partial \ln S(t)}{\partial S(t)} \mathrm{d} W(t)+[\ln Y(t) S(t)-\ln S(t)] \\
\mathrm{d} \ln S(t)=(\mu-\lambda k) S(t) \frac{1}{S(t)} \mathrm{d} t+\frac{\sigma^{2}(t) S(t)^{2}}{2}\left(\frac{1}{S(t)^{2}}\right) \mathrm{d} t \\
+\sigma(t) S(t) \frac{1}{S(t)} \mathrm{d} W(t)+[\ln Y(t)+\ln S(t)-\ln S(t)] \\
\mathrm{d} \ln S(t)=(\mu-\lambda k) \mathrm{d} t-\frac{\sigma^{2}(t)}{2} \mathrm{~d} t+\sigma(t) \mathrm{d} W(t)+\ln Y(t) \\
\ln S(t)=\left(\mu-\frac{\sigma^{2}}{2}-\lambda k\right) t+\sigma(t)[W(t)-W(t)]+\sum_{i=1}^{N(t)} \ln Y(t) \\
S(t)=S(0) \exp \left[\left(\mu-\frac{\sigma^{2}}{2}-\lambda k\right) t+\sigma(t) W(t)\right]+\exp \left[\sum_{i=1}^{N(t)} \ln Y(t)\right] \\
S(t)=S(0) \exp \left\{\left(\mu-\frac{\sigma^{2}}{2}-\lambda k\right) t+\sigma(t) W(t)\right\} \prod_{i=1}^{N(t)} \ln Y_{i}(t)
\end{gathered}
$$

\subsubsection{Density of Jump Distribution}

From Equation (12) an explicit solution for the JDM is

$$
\begin{aligned}
& S(t)= S(0) \exp \left[\left(\mu-\frac{\sigma^{2}}{2}-\lambda k\right) t+\sigma(t) W(t)\right] \prod_{i=1}^{N(t)} \ln Y_{i}(t) \\
&\left(\frac{S(t)}{S(0)}\right)=\mathrm{e}^{\sigma W(t)+\left(\mu-\lambda k-\frac{\sigma^{2}}{2}\right) t} \prod_{i=1}^{N(t)} \ln Y_{i}(t) \\
& \log \left(\frac{S(t)}{S(0)}\right)=\sigma W(t)+\left(\mu-\lambda k-\frac{\sigma^{2}}{2}\right) t+\sum_{i=1}^{j} V_{i}
\end{aligned}
$$

where $V=\ln Y(t)$ (this is Kou's substitution).

Hence the log-return density $\left(\log \left(\frac{S(t)}{S(0)}\right)\right)$ is normally distributed with mean

$$
\begin{aligned}
& \left(\sigma W(t)+\left(\mu-\lambda k-\frac{\sigma^{2}}{2}\right) t\right) \text { and variance }\left(\sigma^{2} t+j \delta\right) . \text { That is } \\
& \log \left(\frac{S(t)}{S(0)}\right) \sim \mathcal{N}\left(\sigma W(t)+\left(\mu-\lambda k-\frac{\sigma^{2}}{2}\right) t, \sigma^{2} t+j \delta\right) .
\end{aligned}
$$

The related probability density at time $t$ is

$$
\psi_{t}(y)=\mathrm{e}^{-\lambda t} \sum_{j=0}^{\infty} \frac{(\lambda t)^{j} \exp \left\{-\frac{\left(y-\left(\mu-\lambda k-\frac{\sigma^{2}}{2}\right) t-j m\right)^{2}}{2\left(\sigma^{2} t+j \delta^{2}\right)}\right\}}{j ! \sqrt{2 \pi\left(\sigma^{2} t+j \delta^{2}\right)}}
$$




\subsubsection{Merton and Kou's Models}

\section{- Merton's Representation}

Merton formally represented his model of the dynamics of the stock price as

$$
\frac{\mathrm{d} S(t)}{S(t-)}=(\alpha-\kappa \lambda) \mathrm{d} t+\sigma \mathrm{d} Z+\mathrm{d} q(t)
$$

where

$\alpha$ is the instantaneous expected return on the stock;

$\sigma^{2}$ is the instantaneous variance of the return on the stock;

$\lambda$ is the mean number of arrivals per unit time;

$\mathrm{d} Z$ is a standard Wiener process;

$q(t)$ is the Poisson process independent Wiener process $\mathrm{dZ}$ such that in a time interval $h$,

$P_{r}\{$ the jumps event does not occur in the interval $(t, t+h)\}=1-\lambda h+o(h)$

$P_{r}\{$ the jump event occurs once in the interval $(t, t+h)\}=\lambda t+o(h)$

$P_{r}\{$ the jumps event occurs more than once in the interval $(t, t+h)\}=o(h)$

where $o(h)$ is the asymptotic order symbol defined by $\psi(h)=o(h)$ if $\lim _{h \rightarrow 0}[\psi(h) / h]=0$

$$
\kappa \equiv \mathcal{E}(Y-1)=\mathcal{E}(Y)-1
$$

$\mathcal{E}$ is the expectation operator over the random variable $Y$.

Merton assumed that if $\alpha, \lambda, \kappa, \sigma$ are constants then Equation (14) has the solution

$$
S(t)=S(0) \exp \left\{\left(\alpha-\frac{\sigma^{2}}{2}-\lambda k\right) t+\sigma Z(t)\right\} Y(n)
$$

where

$$
Y(n)= \begin{cases}1 & \text { if } n=0 \\ \prod_{j=1}^{n} Y_{j} & \text { if } n \geq 1\end{cases}
$$

\section{- Kou's Double Exponential Model}

In Kou's model, the stochastic differential representing the return of the stock under the physical measure $\mathbb{P}$ is given as

$$
\frac{\mathrm{d} S(t)}{S(t-)}=\mu \mathrm{d} t+\sigma \mathrm{d} W(t)+\mathrm{d}\left(\sum_{i=1}^{N(t)}\left(V_{i}-1\right)\right)
$$

where $W(t)$ is a standard Brownian motion, $N(t)$ is a Poisson process with rate $\lambda$, and $V_{i}$ is a sequence of independent identically distributed (i.i.d.) nonnegative random variables such that $Y=\log V$ has an asymmetric double exponential distribution with the density

$$
f(y)=p \cdot \eta_{1} \mathrm{e}^{-\eta_{1} y} \mathbb{I}_{(y \geq 0)}+q \cdot \eta_{2} \mathrm{e}^{-\eta_{2} y} \mathbb{I}_{(y<0)}
$$




$$
\eta_{1}>1, \eta_{2}>0
$$

where $p, q \geq 0, p+q=1$, represent the probabilities of upward and downward jumps.

$$
\log (V)=Y^{\stackrel{d}{=}} \begin{cases}\xi^{+} & \text {with probability } p \\ -\xi^{-} & \text {with probability } q\end{cases}
$$

where $\xi^{+}$and $\xi^{-}$are exponential random variables with means $1 / \eta_{1}$ and $1 / \eta_{2}$, respectively, and the notation $\stackrel{d}{=}$ means equal in distribution. The solution to Kou's model gives the dynamics of the stock price as

$$
S(t)=S(0) \exp \left\{\left(\mu-\frac{\sigma^{2}}{2}\right) t+\sigma(t) W(t)\right\} \prod_{i=1}^{N(t)} V_{i}
$$

\subsection{Monte Carlo Simulation}

Monte Carlo simulation of the jump diffusion model is carried out by simulating paths of a finite sample of the process $S(t) ; t \in[0, T]$. Sample paths of $S(t)$ is obtained over fixed set of dates $0=t_{0}<t_{1}<\cdots<t_{n}=T$ such that the observation times are equally spaced and $\Delta t=t_{i+1}-t_{i}=1$ day .

The discretization representation

$$
S\left(t_{i+1}\right)=S\left(t_{i}\right) \mathrm{e}^{\left(\mu-\frac{\sigma^{2}}{2}\right)\left(t_{i+1}-t_{i}\right)+\sigma\left[W\left(t_{i+1}\right)-W\left(t_{i}\right)\right]} \prod_{j=N\left(t_{i+1}\right)+1}^{N\left(t_{i+1}\right)} Y_{j}(t)
$$

is employed.

Direct simulation from the representation in Equation (15) is possible but in this case, it is appropriate to set $X(t)=\ln S(t)$ and write

$$
\begin{aligned}
X\left(t_{i+1}\right)= & X\left(t_{i}\right)+\left(\mu-\frac{\sigma^{2}}{2}\right)+\left(t_{i+1}-t_{i}\right) \\
& +\sigma(t)\left[W\left(t_{i+1}\right)-W\left(t_{i}\right)\right]+\sum_{j=N\left(t_{i+1}\right)+1}^{N\left(t_{i+1}\right)} \ln Y_{j}
\end{aligned}
$$

where the product over $j$ is equal to 1 if $N\left(t_{i+1}\right)=N\left(t_{i}\right)$. This recursion replaces products with sums and it is preferable.

The procedure can be summarized into the following steps:

1) Generate $\mathcal{Z} \sim \mathcal{N}(0,1)$;

2) Generate $\mathcal{Z} \sim$ Poisson $\left(\lambda\left(t_{i+1}-t_{i}\right)\right)$ if $n=0$, set $\mathcal{M}=0$ and go to Step 4;

3) Generate $\ln Y_{1}, \cdots, \ln Y_{N}$ from the common distribution and set $M=\ln Y_{1}+\cdots+\ln Y_{N}$;

4) Set $X\left(t_{i+1}\right)=X\left(t_{i}\right)+\left(\mu-\frac{1}{2} \sigma^{2}\right) \Delta t+\sigma \sqrt{\Delta t} \mathcal{Z}+\mathcal{M}$.

The parameters for the simulation are estimated from GSE historical market data, specifically the daily log-returns of closing stock prices from January 3 , 2017 to December 29, 2017. There are 247 daily closings for stock prices in the period and $\Delta t$ is set as 


$$
\Delta t=\frac{1}{\text { Trading Days }}=\frac{1}{247}=0.004
$$

The JDM is a five-set parameter model admitting the mean return rate $\mu$, volatility of the diffusion process $\sigma^{2}$, the log-return mean of the jump sizes $m$, variance of the jump sizes $\delta^{2}$ and the jump intensity of the Poisson process $\lambda$. In the simulation procedure the return data is divided into two groups $\mathcal{D}$ and $\mathcal{J}$. Group $\mathcal{D}$ includes log-returns with absolute value less than $\varepsilon$. For this group there are no jumps and $\mu$ and $\sigma$ are estimated from the historical data. Group $\mathcal{J}$ represents the jumps. In determining whether a jump has occurred, the decision rule is that a jump occurs if the absolute value of the log-return is larger than some positive value $\varepsilon$, In this study we set $\varepsilon=0.1$. This means that if there is a daily price change of $10 \%$ or more it is considered as a jump from the previous price. The mean jump height $m$ is determined from the average of the jump sizes over the year. $\delta$ is the standard deviation from the mean jump sizes. The parameters for the simulation for all stocks are given in Table A1 in Appendix. For example, the estimated parameters for the Standard Chartered Bank are: $\mu=0.00295, \sigma^{2}=0.0217, \lambda=4, \quad m=0.12, \delta^{2}=0.01$ and for SIC Insurance, $\mu=-0.0074, \sigma^{2}=0.037589, \lambda=12, \quad m=0.14, \delta^{2}=0.03$.

\section{Results}

As stated earlier, if the stock price follows GBM, the empirical returns should be at least moderately close to a normal density; otherwise the returns will have jumps or will follow some other appropriate distribution. Consequently, the properties of the first four moments, including skewness and excess kurtosis are employed to determine whether a simulated stock follows JDM or GBM. The moments and properties of skewness and kurtosis of the simulated stock prices are thus compared to the observed market data. The parameters of the simulated stock paths and the realized stock prices are presented in Table A2 in the Appendix. Stocks listed 1 - 9 in the table have means and variances that match the parameters of the actual stocks. In addition, the simulated paths also match the high skewness and excess kurtosis shown by the actual stock paths. This shows that the JDM model is more suited to modelling these stocks. Stocks listed 10 25 on the other hand, have means and variances that match the parameters of the actual stocks. In addition, the simulated paths also match the low skewness and low kurtosis shown by the actual stock paths. This shows that the GBM is more suited to modelling these stocks. These results are further established by the graphs of the simulated stocks. Figure 5(a) and Figure 5(b) show the plots of simulated stock paths that follow the jump diffusion. Figure 5(c) and Figure 5(d) also show the simulated paths of some stocks that follow GBM. The trajectories are purely continuous and can be modelled accurately by diffusion models. The prices of stocks numbered 26 - 36 in Table A2 either did not change throughout the year or changed at only periodic times. The return distributions usually produced zero means and zero variances. 


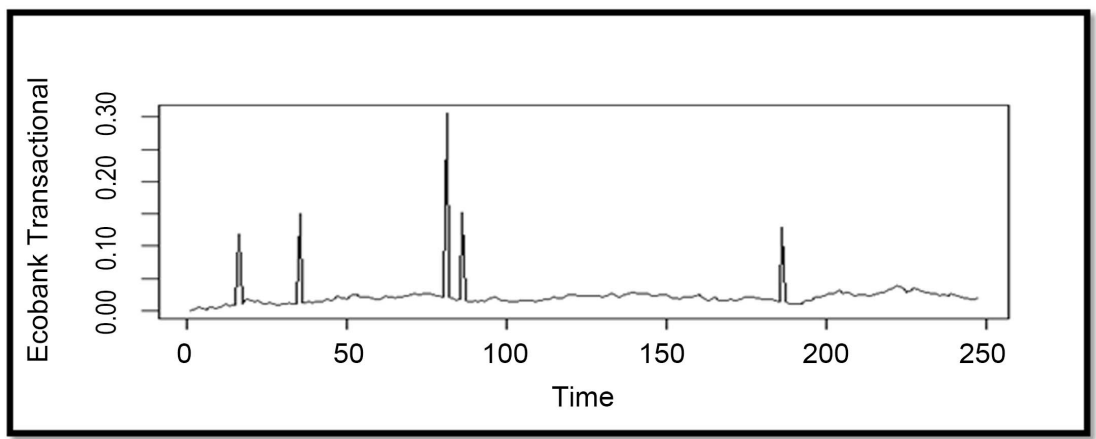

(a)

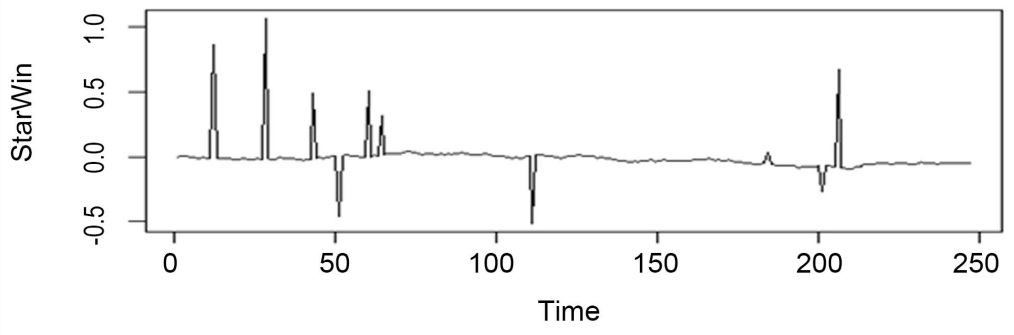

(b)

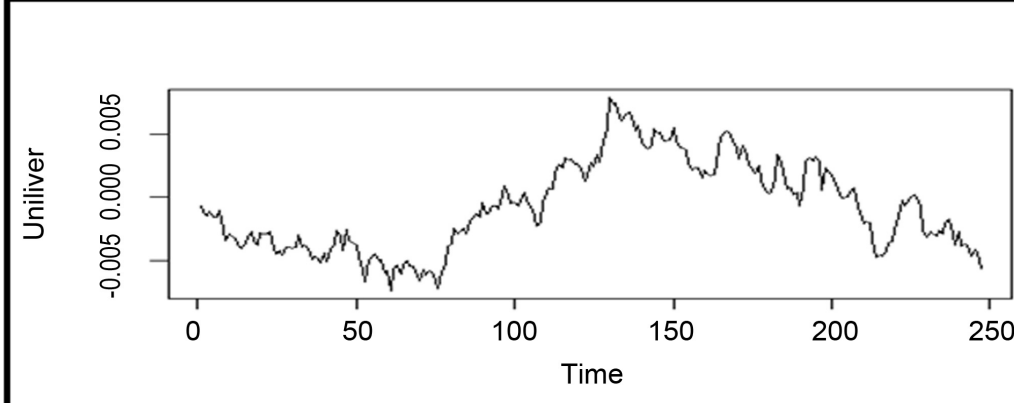

(c)

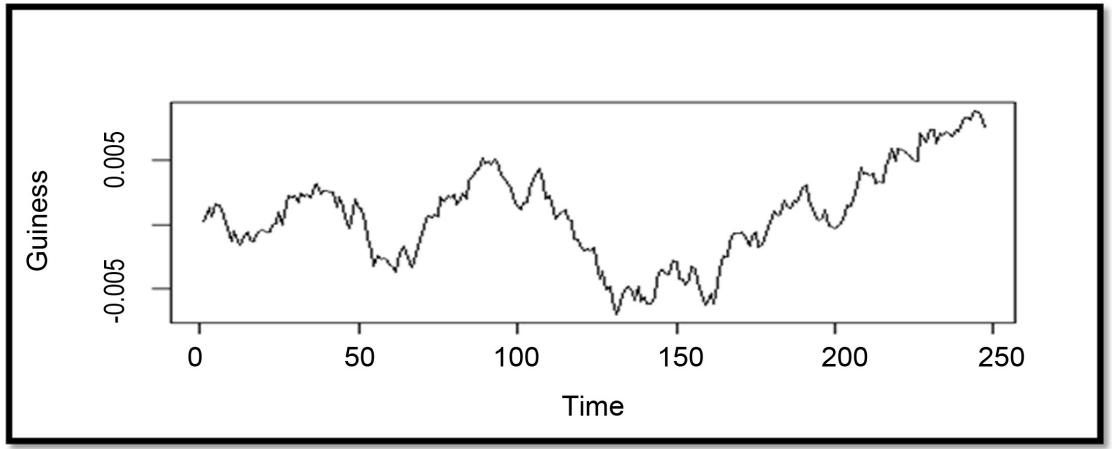

(d)

Figure 5. (a) Simulated stock having continuous path with jumps; (b)Simulated stock having continuous path with jumps; (c) Simulated stock with continuous path; (d) Simulated stock with continuous path.

\section{Conclusions}

In this paper, significant progress has been made towards simplifying the ma- 
thematics of developing the jump diffusion model. The results from theoretical and empirical studies of stock behaviour have also given further insights into the understanding of the stock market in Ghana. When the theoretical model is used to simulate the log returns of stock prices and compared to the actual stock data in 2018 , it is determined that out of the thirty-six (36) listed stocks, nine (9) follow paths that can be modeled by jump diffusion models. Nineteen stocks were found to follow continuous paths and can be modeled as by diffusion models. Thus, the theoretical models simulating the path of the stocks show that the Jump Diffusion Model and Geometric Brownian Motion are possible models for examining stocks on the exchange. The results confirm our assertion that no single model can be used to predict stock behaviour on the exchange.

Ten stocks exhibited paths that are neither purely continuous nor continuous with jumps. These stocks have prices that remain constant for long periods and only change in price at intermittent periods. They therefore have zero or values close to zero in their return distributions and thus cannot be modelled by any of the two models. This shows that the present state of understanding of the stock behaviour on the exchange is far from being conclusive. Further studies are required to completely model the behaviour of the stocks. To pursue for further research, a new model which can track the trajectories of such stocks and can be used to price derivatives on the simulated prices as well as to the real data in the Ghanaian market is required.

\section{Conflicts of Interest}

The authors declare no conflicts of interest regarding the publication of this paper.

\section{References}

[1] Antwi, O. (2017) Stochastic Modeling of Stock Price Behavior on Ghana Stock Exchange. International Journal of Systems Science and Applied Mathematics, 2 116-125. https://doi.org/10.11648/j.ijssam.20170206.12

[2] Bachelier, L. (1900) Théorie de la speculation. Annales Scientifiques de l'Ecole Normale Supérieur, 17, 21-86. https://doi.org/10.24033/asens.476

[3] Samuelson, P.A. (1965) Proof That Properly Anticipated Prices Fluctuate Randomly. Industrial Management Review, 6, 41-49.

[4] Black, F. and Scholes, M. (1973) The Pricing of Options and Corporate Liabilities. Journal of Political Economics, 81, 637-659. https://doi.org/10.1086/260062

[5] Merton, R.C. (1976) Option Pricing When Underlying Stock Returns Are Discontinuous. Journal of Financial Economics, 3, 125-144. https://doi.org/10.1016/0304-405X(76)90022-2

[6] Kou, S.G. and Wang, H. (2004) Option Pricing under a Double Exponential Jump Diffusion Model. Management Science, 50, 1178-1192. https://doi.org/10.1287/mnsc.1030.0163

[7] Madan, D.B. and Seneta, E. (1990) The Variance Gamma Model for Share Market Returns. The Journal of Business, 63, 511-524. https://doi.org/10.1086/296519

[8] Matsuda, K. (2004) Introduction to Merton Jump Diffusion Model. Department of 
Economics, The Graduate Center, The City University of New York, New York.

[9] Amin, K.I. (1993) Jump Diffusion Option Valuation in Discrete Time. The Journal of Finance, 48, 1833-1863. https://doi.org/10.1111/j.1540-6261.1993.tb05130.x

[10] Cox, J., Ross, S. and Rubinstein, M. (1979) Option Pricing: A simplified approach. Journal of Financial Economics, 7, 229-263. https://doi.org/10.1016/0304-405X(79)90015-1

[11] Cont, R. and Tankov, P. (2004) Financial Modelling with Jump Processes. Chapman and Hall/CRC, New York. https://doi.org/10.1201/9780203485217

[12] Hull, J. and White, A. (1987) The Pricing of Options on Assets with Stochastic Volatilities. The Journal of Finance, 42, 281-300. https://doi.org/10.1111/j.1540-6261.1987.tb02568.x

[13] Heston, S.L. (1993) A Closed-Form Solution for Options with Stochastic Volatility with Applications to Bond and Currency Options. Review of Financial Studies, 6, 327-343. https://doi.org/10.1093/rfs/6.2.327

[14] Duffie, D., Pan, J. and Singleton, K. (1998) Transform Analysis and Asset Pricing for Affine Jump-Diffusions. Econometrica, 68, 1343-1376. https://doi.org/10.1111/1468-0262.00164

[15] Chernov, M., et al. (2003) Alternative Models for Stock Price Dynamics. Journal of Econometrics, 116, 225-257. https://doi.org/10.1016/S0304-4076(03)00108-8

[16] Barndorff-Nielsen, O.E. and Shephard, N. (2001) Non-Gaussian Ornstein-Uhlenbeck Based Models and Some of Their Uses in Financial Economics (With Discussion). Journal of Royal Statistical Society Series B, 63, 167-241. https://doi.org/10.1111/1467-9868.00282

[17] Duffle, D. (1988) Security Markets: Stochastic Models. Academic Press, Boston.

[18] Cox, J.C. and Ross, S.A. (1976) The Valuation of Options for Alternative Stochastic Processes. Journal of Financial Economics, 3, 145-166. https://doi.org/10.1016/0304-405X(76)90023-4

[19] Davydov, D. and Linetsky, V. (2001) Pricing and Hedging Path-Dependent Options under the CEV Process. Management Science, 47, 949-965. https://doi.org/10.1287/mnsc.47.7.949.9804

[20] Mandelbrot, B. (1963) The Variation of Certain Speculative Prices. Journal of Business, 36, 394-419. https://doi.org/10.1086/294632

[21] Barndorff-Nielsen, O.E. and Shephard, N. (2004) Power and Bipower Variation with Stochastic Volatility and Jumps. Journal of Financial Econometrics, 2, 1-37. https://doi.org/10.1093/jifinec/nbh001

[22] Samorodnitsky, G. and Taqqu, M.S. (1994) Stable Non-Gaussian Random Processes: Stochastic Models with Infinite Variance. Chapman \& Hall, New York.

[23] Blattberg, R.C. and Gonedes, N.J. (1974) A Comparison of the Stable and Student Distributions as Statistical Models for stock prices. Journal of Business, 47, 244-280. https://doi.org/10.1086/295634

[24] Glassserman, P. (2004) Monte Carlo Methods in Financial Engineering. Springer-Verlag, New York.

[25] Hanson, F.B. (2007) Applied Stochastic Processes and Control for Jump-Diffusions: Modeling Analysis and Computation. SIAM, Philadelphia.

[26] Hanson, F.B. and Westman, J.J. (2002) Jump-Diffusion Stock Return Models in Finance: Stochastic Process Density with Uniform-Jump Amplitude. In: Gilliam, D.S. and Rosenthal, J., Eds., Proceedings of the 15th International Symposium on 
Mathematical Theory of Networks and Systems, University of Notre Dame, South Bend, IN, 1-7.

[27] Alexandros, B. and Roberts, G.O. (2005) Exact Simulation of Diffusions. Annals of Applied Probability, 15, 2422-2444. https://doi.org/10.1214/105051605000000485

[28] Casella, B. and Roberts, G. (2011) Exact Simulation of Jump-Diffusion Processes with Monte Carlo Applications Methodological Computation. Methodology and Computing in Applied Probability, 13, 449-473. https://doi.org/10.1007/s11009-009-9163-1

[29] Pollock, M., Johansen, A.M and Roberts, G.O. (2016) On the Exact and Strong Simulation of (Jump) Diffusions. Bernoulli, 22, 794-856.

https://doi.org/10.3150/14-BEJ676 


\section{Appendix}

Table A1. Input parameters for simulation.

\begin{tabular}{|c|c|c|c|c|c|c|c|c|c|c|c|c|c|}
\hline & Stock & $\mu$ & $\sigma$ & $\lambda$ & $m$ & $\delta$ & & Stock & $\mu$ & $\sigma$ & $\lambda$ & $m$ & $\delta$ \\
\hline 1 & Access Bank Ghana PLC & 0.0000 & 0.029841 & 0.00 & 0.00 & 0.00 & 19 & $\begin{array}{c}\text { Golden Star Resources } \\
\text { Limited }\end{array}$ & -0.00011 & 0.001723 & 0.00 & 0.00 & 0.00 \\
\hline 2 & African Champion Limited & 0.00 & 0.00 & 7.00 & 0.45 & 0.23 & 20 & Golden Web Limited & 0.00 & 0.00 & 0.00 & 0.00 & 0.00 \\
\hline 3 & $\begin{array}{c}\text { Agricultural Development } \\
\text { Bank }\end{array}$ & 0.001715 & 0.012896 & 1.00 & 0.20 & 0.01 & 21 & HFC Bank (Ghana) Limited & 0.002508 & 0.021791 & 0.00 & 0.00 & 0.00 \\
\hline 4 & AngloGold Ashanti Limited & 0.00000 & 0.0000 & 0.00 & 0.00 & 0.00 & 22 & $\begin{array}{l}\text { Mega African } \\
\text { Capital Limited }\end{array}$ & -0.00145 & 0.00015 & 0.00 & 0.00 & 0.00 \\
\hline 5 & Aluworks Limited & 0.000543 & 0.016869 & 2.00 & 0.13 & 0.004 & 23 & $\begin{array}{l}\text { Mechanical Lloyd } \\
\text { Co. Limited }\end{array}$ & -0.00372 & 0.020868 & 0.00 & 0.00 & 0.00 \\
\hline 6 & $\begin{array}{c}\text { Ayrton Drug Manufacturing } \\
\text { Limited }\end{array}$ & -0.00074 & 0.011624 & 1.00 & 0.19 & 0.003 & 24 & $\begin{array}{c}\text { Pioneer } \\
\text { Kitchenware Limited }\end{array}$ & 0.00 & 0.00 & 0.00 & 0.00 & 0.00 \\
\hline 7 & $\begin{array}{c}\text { Benso Oil } \\
\text { Palm Plantation }\end{array}$ & 0.004387 & 0.018568 & 4.00 & 0.12 & 0.01 & 25 & PBC Limited & 0.01 & 0.04573 & 12.00 & 0.20 & 0.03 \\
\hline 8 & Cal Bank Limited & 0.001428 & 0.031976 & 9.00 & 0.14 & 0.02 & 26 & PZ Cussons Ghana Limited & -0.00039 & 0.006077 & 0.00 & 0.00 & 0.00 \\
\hline 9 & Clydestone (Ghana) Limited & 0.0000 & 0.0000 & 0.00 & 0.00 & 0.00 & 27 & $\begin{array}{c}\text { Standard Chartered Bank } \\
\text { Ghana Limited }\end{array}$ & 0.002954 & 0.021696 & 4.00 & 0.12 & 0.01 \\
\hline 10 & Camelot Ghana Limited & -0.00035 & 0.005548 & 0.00 & 0.00 & 0.00 & 28 & $\begin{array}{c}\text { SIC Insurance Company } \\
\text { Limited }\end{array}$ & -0.00074 & 0.037589 & 12.00 & 0.14 & 0.03 \\
\hline 11 & Cocoa Processing Co. Limited & 0.0000 & 0.072554 & 0.00 & 0.00 & 0.00 & 29 & Starwin Products Limited & 0.0100 & 0.084415 & 14.00 & 0.35 & 0.57 \\
\hline 12 & Ecobank Ghana Ltd. & 0.000636 & 0.000176 & 0.00 & 0.00 & 0.00 & 30 & $\begin{array}{c}\text { Societe Generale Ghana } \\
\text { Limited }\end{array}$ & 0.001137 & 0.010978 & 0.00 & 0.00 & 0.00 \\
\hline 13 & Enterprise Group Limited & 0.00176 & 0.018091 & 1.00 & 0.11 & 0.00 & 31 & Sam Woode Limited & 0.000907 & 0.014227 & 0.00 & 0.00 & 0.00 \\
\hline 14 & Ecobank Transnational Inc. & 0.001911 & 0.034102 & 2.00 & 0.57 & 0.61 & 32 & Trust Bank Ghana Limited & 0.001208 & 0.023732 & 6.00 & 0.14 & 0.01 \\
\hline 15 & Fan Milk Limited & 0.00186 & 0.01192 & 1.00 & 0.10 & 0.00 & 33 & $\begin{array}{c}\text { Total Petroleum Ghana } \\
\text { Limited }\end{array}$ & 0.00231 & 0.013432 & 1.00 & 0.12 & 0.00 \\
\hline 16 & GCB Bank Limited & 0.001376 & 0.011604 & 0.00 & 0.00 & 0.00 & 34 & Tullow Oil Plc & -0.00183 & 0.015226 & 2.00 & 0.16 & 0.01 \\
\hline 17 & $\begin{array}{c}\text { Guinness Ghana Breweries } \\
\text { Limited }\end{array}$ & 0.000952 & 0.000115 & 0.00 & 0.00 & 0.00 & 35 & Unilever Ghana Limited & 0.001672 & 0.01281 & 0.00 & 0.00 & 0.00 \\
\hline 18 & Ghana Oil Company Limited & 0.003635 & 0.011702 & 0.00 & 0.00 & 0.00 & 36 & UT Bank Limited & 0.003984 & 0.066734 & 0.00 & 0.00 & 0.00 \\
\hline
\end{tabular}

Table A2. Parameters for simulated and actual log returns of stock prices for 2018.

\begin{tabular}{|c|c|c|c|c|c|c|c|c|c|c|c|c|c|}
\hline & Stock & Stock Path & Mean & Variance & Skew & Kurtosis & & Stock & Stock Path & Mean & Variance & Skew & Kurtosis \\
\hline \multirow{2}{*}{1} & \multirow{2}{*}{ Aluworks Limited } & Actuals & -0.0028 & 0.0007 & 13.9989 & 13.4400 & \multirow{2}{*}{19} & \multirow{2}{*}{$\begin{array}{c}\text { Golden Web } \\
\text { Limited }\end{array}$} & Actuals & 0.0278 & 0.1217 & 1.1106 & 0.5173 \\
\hline & & Predicted & -0.0005 & 0.0001 & 13.6600 & 20.3400 & & & Predicted & 0.0007 & 0.0000 & -0.2600 & -0.8500 \\
\hline \multirow{2}{*}{2} & Benso Oil Palm & Actuals & -0.0008 & 0.0002 & 9.5710 & 10.1330 & \multirow{2}{*}{20} & \multirow{2}{*}{$\begin{array}{l}\text { HFC Bank } \\
\text { (Ghana) Ltd. }\end{array}$} & Actuals & 0.00591 & 0.00994 & 1.96957 & 1.5447 \\
\hline & Plantation & Predicted & -0.0005 & 0.0003 & 15.8500 & 9.7300 & & & Predicted & 0.00641 & 0.00007 & 1.0600 & -1.1100 \\
\hline \multirow{2}{*}{3} & Ecobank & Actuals & 0.0020 & 0.0014 & 10.4612 & 12.9413 & \multirow{2}{*}{21} & Mechanical & Actuals & -0.0007 & 0.00401 & -1.6125 & 1.6063 \\
\hline & Transnational Inc. & Predicted & 0.0018 & 0.0001 & 10.5538 & 21.2631 & & Lloyd Co. Ltd. & Predicted & 0.0000 & 0.0000 & 0.0000 & 0.0000 \\
\hline \multirow{2}{*}{4} & \multirow{2}{*}{ Fan Milk Limited } & Actuals & -0.0032 & 0.0003 & 4.6480 & 33.2835 & \multirow{2}{*}{22} & PZ Cussons & Actuals & 0.00501 & 0.17822 & 0.03927 & 15.1281 \\
\hline & & Predicted & -0.0013 & 0.0001 & 7.7800 & 24.3400 & & Ghana Ltd. & Predicted & 0.00005 & 0.00002 & 0.4000 & -0.5900 \\
\hline
\end{tabular}




\section{Continued}

\begin{tabular}{|c|c|c|c|c|c|c|c|c|c|c|c|c|c|}
\hline \multirow{2}{*}{5} & \multirow{2}{*}{$\begin{array}{l}\text { Produce Buying } \\
\text { Company Ltd. }\end{array}$} & Actuals & 0.00778 & 0.02473 & 13.5271 & 20.5417 & \multirow{2}{*}{23} & \multirow{2}{*}{$\begin{array}{l}\text { SIC Insurance } \\
\text { Company Ltd. }\end{array}$} & Actuals & 0.0026 & 0.00162 & 0.96564 & 7.0041 \\
\hline & & Predicted & 0.00314 & 0.00205 & 13.9200 & 16.4300 & & & Predicted & -0.0692 & 0.00208 & 0.9400 & 3.0050 \\
\hline \multirow[b]{2}{*}{6} & Standard & Actuals & 0.00075 & 0.00045 & 10.9790 & 28.5262 & \multirow[b]{2}{*}{24} & Societe & Actuals & -0.0004 & 0.00054 & -0.58737 & 1.2515 \\
\hline & $\begin{array}{c}\text { Chartered Bank } \\
\text { Ghana. Ltd. }\end{array}$ & Predicted & 0.01804 & 0.00033 & 6.3900 & 12.600 & & $\begin{array}{c}\text { Generale } \\
\text { Ghana Ltd. }\end{array}$ & Predicted & 0.0000 & 0.0000 & 0.0000 & 0.0000 \\
\hline \multirow{2}{*}{7} & Starwin Products & Actuals & -0.00164 & 0.01773 & -10.0784 & 8.53299 & \multirow{2}{*}{25} & Total & Actuals & -0.0002 & 0.00071 & -1.6952 & 2.04099 \\
\hline & Ltd. & Predicted & 0.10701 & 0.03703 & 12.4100 & 21.2100 & & Ghana Ltd. & Predicted & 0.0082 & 0.00049 & 0.1800 & 1.5700 \\
\hline \multirow{2}{*}{8} & Trust Bank Ghana & Actuals & 0.0017 & 0.0007 & 13.2535 & 31.9042 & \multirow{2}{*}{26} & Unilever & Actuals & 0.00132 & 0.00008 & 0.72769 & 1.01634 \\
\hline & Ltd. & Predicted & 0.03945 & 0.00020 & 7.2800 & 28.9600 & & Ghana Ltd. & Predicted & 0.01101 & 0.00231 & 0.7500 & 1.0002 \\
\hline 9 & Tullow Oil Plc & Actuals & 0.00147 & 0.00022 & 10.7760 & 16.5308 & 27 & Access Bank & Actuals & -0.0005 & 0.00241 & -0.30962 & 8.1141 \\
\hline \multirow{2}{*}{10} & & Actuals & 0.0000 & 0.0000 & 0.0000 & 0.0000 & \multirow{2}{*}{28} & AngloGold & Actuals & 0.0000 & 0.0000 & 0.0000 & 0.0000 \\
\hline & & Predicted & 0.0005 & 0.0020 & 0.9800 & 1.1300 & & & Predicted & 0.0000 & 0.0000 & 0.0000 & 0.0000 \\
\hline \multirow[t]{2}{*}{11} & $\begin{array}{l}\text { Ayrton Drug } \\
\text { Manufacturing }\end{array}$ & Actuals & -0.0014 & 0.0005 & -0.2615 & 0.0723 & \multirow[t]{2}{*}{29} & $\begin{array}{c}\text { Clydestone } \\
\text { (Ghana) }\end{array}$ & Actuals & 0.0000 & 0.0000 & 0.0000 & 0.0000 \\
\hline & Limited & Predicted & -0.0080 & 0.0000 & 0.4900 & -0.2400 & & Limited & Predicted & 0.0000 & 0.0000 & 0.0000 & 0.0000 \\
\hline \multirow{2}{*}{12} & \multirow{2}{*}{ Cal Bank Limited } & Actuals & -0.0004 & 0.0007 & -0.8781 & 1.9381 & \multirow{2}{*}{30} & $\begin{array}{c}\text { Cocoa } \\
\text { Processing Co }\end{array}$ & Actuals & 0.0000 & 0.0000 & 0.0000 & 0.0000 \\
\hline & & Predicted & -0.0004 & 0.0012 & 3.0500 & 0.5500 & & Limited & Predicted & 0.0000 & 0.0000 & 0.0000 & 0.00000 \\
\hline \multirow{2}{*}{13} & Camelot Ghana & Actuals & -0.0004 & 0.0005 & -1.5120 & 3.4298 & \multirow{2}{*}{31} & $\begin{array}{l}\text { Golden Star } \\
\text { Resources }\end{array}$ & Actuals & 0.0000 & 0.0000 & 0.0000 & 0.0000 \\
\hline & Limited & Predicted & 0.0000 & 0.0000 & -0.0300 & -0.8700 & & Limited & Predicted & 0.0000 & 0.0000 & 0.0000 & 0.0000 \\
\hline 14 & Ecobank Ghana & Actuals & -0.0001 & 0.0006 & 0.6055 & 1.9457 & 32 & Mega African & Actuals & 0.0000 & 0.0000 & 0.0000 & 0.0000 \\
\hline \multirow{2}{*}{15} & Enterprise Group & Actuals & -0.0225 & 0.0002 & 1.6500 & 0.2000 & \multirow[t]{2}{*}{33} & $\begin{array}{c}\text { Pioneer } \\
\text { Kitchenware }\end{array}$ & Actuals & -0.0009 & 0.00263 & -0.2852 & 2.2805 \\
\hline & Limited & Predicted & -0.0020 & 0.0003 & -2.2000 & 2.8255 & & Ltd. & Predicted & 0.0000 & 0.0000 & 0.0000 & 0.0000 \\
\hline \multirow[t]{2}{*}{16} & Ghana & Actuals & -0.0004 & 0.0004 & -0.4943 & 1.7835 & 34 & Sam Woode & Actuals & 0.0000 & 0.0000 & 0.0000 & 0.0000 \\
\hline & Limited & Predicted & 0.0086 & 0.0000 & -0.3600 & -1.3400 & 34 & Ltd. & Predicted & 0.0000 & 0.0000 & 0.0000 & 0.0000 \\
\hline 17 & Guinness Ghana & Actuals & 0.0002 & 0.0001 & 0.7534 & 1.2409 & 3 & $\begin{array}{c}\text { Transaction } \\
\text { Solutions }\end{array}$ & Actuals & 0.0000 & 0.0000 & 0.0000 & 0.0000 \\
\hline & Breweries Limited & Predicted & 0.0004 & 0.0000 & -0.1300 & -1.3400 & & (Ghana) Ltd. & Predicted & 0.0000 & 0.0000 & 0.0000 & 0.0000 \\
\hline 18 & Ghana Oil & Actuals & 0.0006 & 0.0004 & 0.5471 & 2.0007 & & & Actuals & 0.0000 & 0.0000 & 0.0000 & 0.0000 \\
\hline & Company Limited & Predicted & 0.0019 & 0.0000 & 2.7494 & 2.0808 & & & Predicted & 0.0000 & 0.0000 & 0.0000 & 0.0000 \\
\hline
\end{tabular}

